\title{
Prevalence of influenza vaccination among physicians and related enhancing and preventing factors in Italy
}

Prevalenza in Italia della vaccinazione anti-influenzale tra i professionisti sanitari e fattori incentivanti e ostacolanti correlati

Alice Mannocci ${ }^{1}$, Paolo Ursillo ${ }^{1}$, Claudio Bontempi ${ }^{1}$, Antonella Sferrazza ${ }^{2}$, Giuseppe La Torre ${ }^{1}$

Clinical Medicine and Public Health Unit, Department of Experimental Medicine, Sapienza University of Rome, Italy Institute of Hygiene, Università Cattolica del Sacro Cuore, Rome, Italy

\section{Abstract}

Introduction: Several studies proved the convenience of vaccinating health care workers (HCWs), especially physicians, and vaccination is recommended by health authorities in many Countries. Nonetheless in Italy only a small part of HCWs get vaccinated. The aim of this study is to conduct a systematic review in order to estimate the pooled prevalence of influenza vaccinations among physicians in Italy and to investigate the enhancing/preventing factors associated with this kind of preventive tool.

Methods: Relevant articles up to $1^{\text {st }}$ May 2010 have been identified through Scopus, PubMed and Google Scholar; data extraction and quality assessment were performed independently by two researchers. The analysis was performed using StatsDirect 2.7.8.

Results: Sixteen studies, performed between 1990 and 2008, reported vaccination rates with pooled prevalence among all HCWs. From nine of them data regarding physicians have been extracted and analysed, finding a pooled proportion of $23.18 \%(95 \% \mathrm{CI}=17.85-28.98 \%)$. One study allowed an analysis of the reasons encouraging and preventing influenza vaccination. The main ones are on one side self protection, and patients' and family's protection, and on the other side "not caring about influenza," followed by "fear of adverse effects" and "belief that vaccine isn't effective."

Discussion: Italy has a good overall influenza vaccination coverage, and national records are available for population aged over 65 years or with chronic illness. Unfortunately there isn't any national record about HCWs or physicians vaccination, and from the data gathered from the studies examined in this analysis vaccination prevalence is low. The reasons brought from physicians are worrying because of their position in the society and in the health care system, in close contact with patients. This shows a great need for well-done information and educational campaigns stressing the importance of prevention.

\section{Keywords}

Influenza vaccination; Physicians; Italy 


\section{Introduction}

Vaccination against seasonal influenza in health care workers (HCWs), and expecially physicians, is recommended by the Italian Ministry of Health and has proven to be a useful device for reducing absenteeism, and for interrupting the contagion chain between patients and HCWs, who often continue their job even if with symptoms of influenza [1]. Besides, if done systematically, this kind of vaccination is useful for an adequate use of the hospital resources.

The convenience of vaccinating HCWs has been proven by several studies [2]; a cost-benefit analysis also proved the efficiency of vaccination strictly from an economical point of view [3].

Despite these evidences, there is a consistent part of the population of physicians which doesn't support, or even oppose, this preventive practice [4-7].

In many European Countries, such as United Kingdom, Germany, France, Spain, vaccination of people working in medical field is perceived as important and this group gets vaccinated more than general population, with percentages ranging from $15 \%$ to $29 \%$ [8]. Vaccination practice is even stronger in Canada, ranging from $35.5 \%$ to $51 \%[9,10]$, and in Australia, 28\% [11].

This doesn't happen in Italy, where the percentage of HCWs that get vaccinated is totally overlapping with the general population, and sometimes even lower. Rates are respectively $11-16 \%$ and $9-13 \%$ from 2004 to 2007 [8].

The aim of this study is to conduct a systematic review in order to:

- Estimate the pooled prevalence of influenza vaccinations among physicians in Italy.

- Investigate the enhancing/hindering factors associated with this kind of vaccination among physicians.

\section{Methods}

\section{Identification of relevant studies}

The research was conducted using medical databases Scopus and PubMed, and the search engine Google Scholar. The research algorithm used in Scopus and PubMed was: (influenza (OR) flu) (AND) vaccination(AND) healthcare (AND) workers (AND) Italy. In Google Scholar we used the simple algorithm: influenza vaccination healthcare workers Italy. The research was concluded May 1st 2010.

The abstracts were examined, and pre-determined inclusion criteria for the studies were: Italian setting, only seasonal flu (not avian or swine flu), English or Italian language. Then we included in the metaanalysis only the articles which showed specifically quantitative and qualitative data about physicians; the others have been used to have a global vision of the context. This lead to a strict selection of the results, especially from Google Scholar, which is highly sensitive, but much less specific.

When the same article was found in more than one database, it was considered once.

Finally, the eligible papers were obtained in full text.

Following data extraction was performed by two independent researchers. Discrepancies were recorded and resolved by discussion. The information extracted were year, setting, study design, population involved in the study and responders, prevalence, and beliefs associated with vaccination.

\section{Quality assessment}

All the selected studies were revised by two different researchers to assess the quality score, according to a score sheet available for observational studies $[12,13]$. Disagreement about quality was solved with a discussion and a second examination. In particular concerning the power of the sample, the 
researchers evaluated number of responders on the total population involved in the studies (see Tables I and II).

\section{Pooled analysis}

The pooled prevalence of influenza vaccination among physicians was calculated considering in the review only the studies reporting data on physicians, and after stratifying quality of the articles (score $\geq 3$; see also the "Quality assessment" Paragraph).

The pooled proportion was calculated as the back-transformation of the weighted mean of the transformed proportion [14], using inverse arcsin variance weights for the fixed effects model and DerSimonian-Laird weights for the random effects model [15]. Together the pooled prevalence with relative 95\% confidence interval (CI) and forest plot was realised. The Cochran chi-square (Cochran Q) test [16] was used to evaluate the between-study heterogeneity in the different groups. Besides, the $\mathrm{I}^{2}$ [17] statistic was calculated as a measure of the proportion of the overall variation attributable to the between-study heterogeneity rather than chance $[17,18]$. The statistical analysis was conducted using StatsDirect statistical software version 2.7.8.

Ideas regarding prevention and encouragement to vaccination have been extracted from all the available studies; they were examined and compared, stressing the relevance of factors reported in different papers.

\section{Results}

\section{Identification of relevant studies}

The flow-chart shown in Figure 1, and built on the basis of PRISMA's indications [19], shows the selection of articles. Using inclusion criteria we found five articles in Google Scholar, ten in PubMed and six in Scopus. Five articles, that were contemporary present in more than one database, were considered once, and one paper was excluded because it criticised vaccination policy without concrete data supporting this hypothesis [20].

The review was performed using 16 articles [1,3-8,21-29]: 15 with a cross-section study design and 1 with a cohort one (Table I). Six papers contained the measure of occurrence of vaccination (prevalence) among physicians; the others were used for qualitative analysis.

\section{Quality assessment}

In all the six articles we calculated the score using the observational studies protocol $[12,13]$. The range of quality obtained was between 1 and 7 (Table I). Three of the studies had a score $\geq 3$.

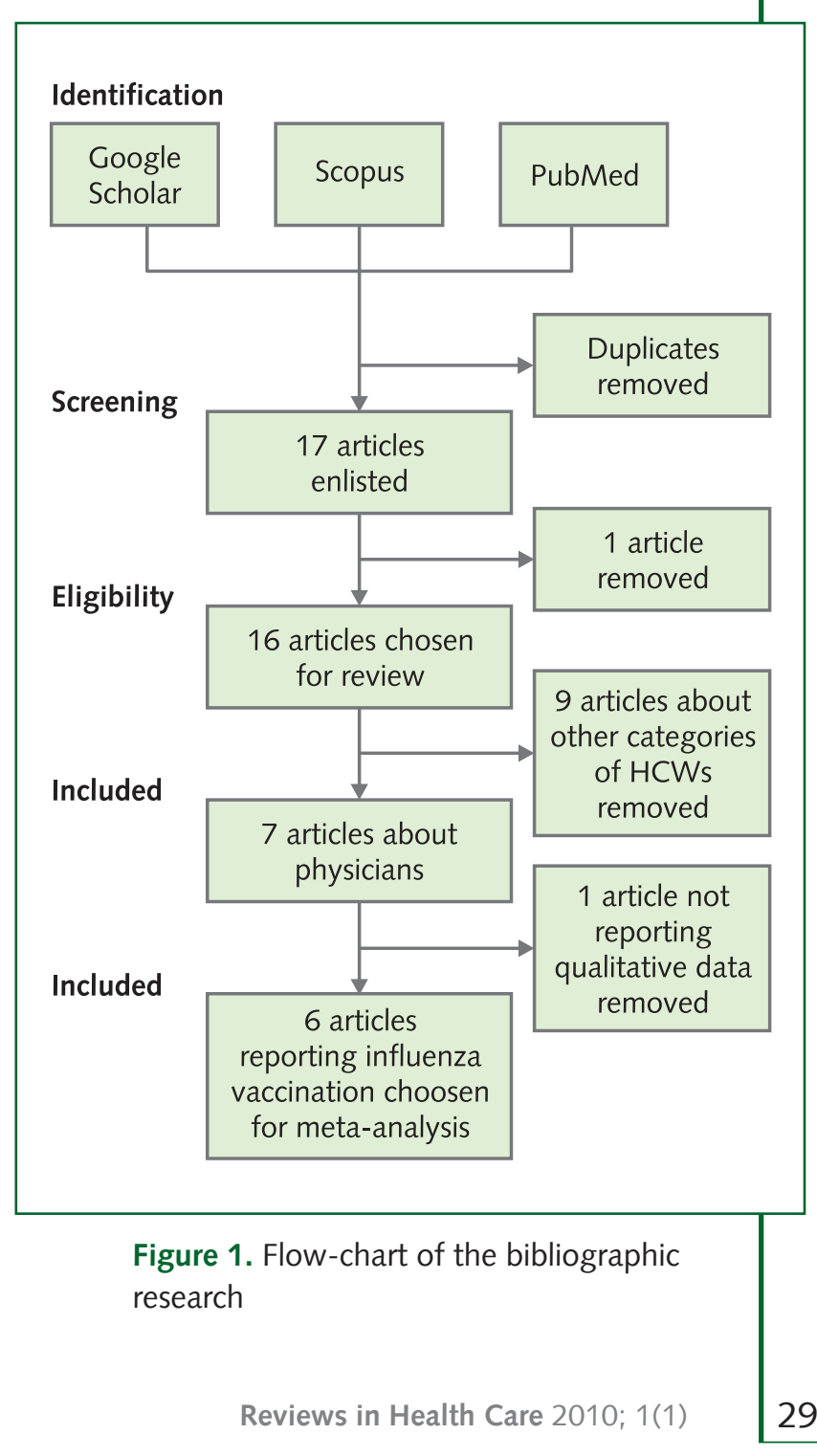




\begin{tabular}{|llcccc|}
\hline \multicolumn{1}{|c}{ Author } & Year & $\begin{array}{c}\text { Presence } \\
\text { of prevalence }\end{array}$ & $\begin{array}{c}\text { Quality } \\
\text { of the study* }\end{array}$ & $\begin{array}{c}\text { Type of population of the study } \\
\text { (phy, nur, anc, oth) }\end{array}$ & $\begin{array}{c}\text { Number } \\
\text { of responders }\end{array}$ \\
\hline Panico [7] & 2010 & Yes & 3 & Phy, nur, oth & 2,079 \\
\hline Esposito [4] & 2008 & Yes & 4 & n.r. & 2,143 \\
Amodio [22] & 2010 & Yes & 4 & Phy, nur, anc, oth & 2,570 \\
\hline La Torre [25] & 2009 & No & 5 & n.r. & 1,960 \\
\hline Blank [8] & 2008 & Yes & 5 & n.r. & 84 \\
\hline Fanetti [23] & 2007 & Yes & 1 & Phy, nur, anc & 1,418 \\
\hline Chittaro [26] & 2009 & Yes & 7 & n.r. & 473 \\
\hline Grandi [1] & 2005 & No & 0 & Phy, nur, anc & Phy, nur, anc \\
\hline Calisto [24] & 2002 & No & 2 & n.r. & 811 \\
\hline Brusaferro [21] & 2004 & Yes & 2 & n.r. & 6,102 \\
\hline Nicholson [27] & 1995 & No & 0 & Phy, nur, oth & n.r. \\
\hline Rizzuto [28] & 2006 & No & 4 & n.r. & 129 \\
\hline Ballada [5] & 1994 & Yes & 2 & n.r. & 1,129 \\
\hline Di Giuseppe [29] & 2007 & No & 6 & Phy, nur, oth & 369 \\
\hline Colombo [3] & 2006 & No & 7 & 214 \\
\hline Piffer [6] & 2000 & Yes & 1 & 815 \\
\hline
\end{tabular}

Table I. Characteristics of the selected studies

* Quality was calculated using protocol of observational studies [12,13]

anc $=$ ancillary worker; n.r. $=$ not reported; nur $=$ nurses; oth $=$ others; phy $=$ physicians

\section{Pooled analysis}

Physicians (Table II, Figure 2), as sustained by many Authors [5,18,19], appear to be the category of HCWs that cares more about vaccination, with a pooled proportion of $23.18 \%(95 \% \mathrm{CI}=17.85$ $28.98 \%$ ). This data are much better than the average population of HCW and even better than nurses and ancillary workers $[5-7,21,22,27]$.

\begin{tabular}{|c|c|c|c|c|c|c|c|c|c|}
\hline & \multirow[b]{2}{*}{ Author } & \multirow[b]{2}{*}{ Year } & \multirow[b]{2}{*}{$\begin{array}{c}\text { Year of } \\
\text { follow-up }\end{array}$} & \multicolumn{4}{|c|}{ Physicians } & \multicolumn{2}{|c|}{ Prevalence $\mathrm{Cl} 95 \%$} \\
\hline & & & & $\begin{array}{l}\text { Vaccinates } \\
\text { (n.) }\end{array}$ & $\begin{array}{c}\text { Responders } \\
\text { (n.) }\end{array}$ & $\begin{array}{l}\text { Workers } \\
\text { in the } \\
\text { hospital } \\
\text { (n.) }\end{array}$ & $\begin{array}{l}\text { Prevalence of } \\
\text { vaccinates in } \\
\text { the responders } \\
\text { sample }(\%)\end{array}$ & Lower & Upper \\
\hline \multirow[t]{2}{*}{1} & \multirow[t]{2}{*}{ Panico [7] } & \multirow[t]{2}{*}{2010} & $2002-03$ & 79 & 409 & 409 & 19.3 & 15.6 & 23.46 \\
\hline & & & $2003-04$ & 81 & 409 & 409 & 19.8 & 16.05 & 24 \\
\hline \multirow[t]{3}{*}{2} & \multirow[t]{3}{*}{ Amodio [22] } & \multirow[t]{3}{*}{2010} & $2005-06$ & 80 & 620 & 620 & 12.9 & 10.36 & 15.8 \\
\hline & & & $2006-07$ & 86 & 648 & 648 & 13.3 & 10.8 & 16.16 \\
\hline & & & $2007-08$ & 71 & 656 & 656 & 10.8 & 8.52 & 13.43 \\
\hline \multirow[t]{3}{*}{3} & \multirow[t]{3}{*}{ Chittaro [26] } & \multirow[t]{3}{*}{2009} & 2004 & 26 & 106 & 117 & 24.5 & 16.67 & 33.81 \\
\hline & & & 2005 & 63 & 106 & 117 & 59.4 & 49.43 & 68.83 \\
\hline & & & 2006 & 48 & 106 & 117 & 45.2 & 35.51 & 55.16 \\
\hline 4 & Brusaferro [21] & 2004 & 1999-00 & 321 & 1,521 & 1,521 & 21.1 & 19.07 & 23.24 \\
\hline 5 & Ballada [5] & 1993 & 1990 & 102 & 781 & 781 & 13 & 10.72 & 15.56 \\
\hline \multirow[t]{2}{*}{6} & Piffer [6] & 2000 & 1998 & 55 & 153 & 874 & 36.2 & 28.59 & 44.35 \\
\hline & Total & & & 1,012 & 5,515 & 6,269 & $23.18^{*}$ & $17.85^{*}$ & $28.98^{*}$ \\
\hline
\end{tabular}

Table II. Prevalence of vaccinates in the selected studies and pooled analysis for physicians

* Pooled prevalence calculated using Random effects (Non-combinability of studies: Cochrane Q: 227,104 $\mathrm{P}<0.0001)$ 


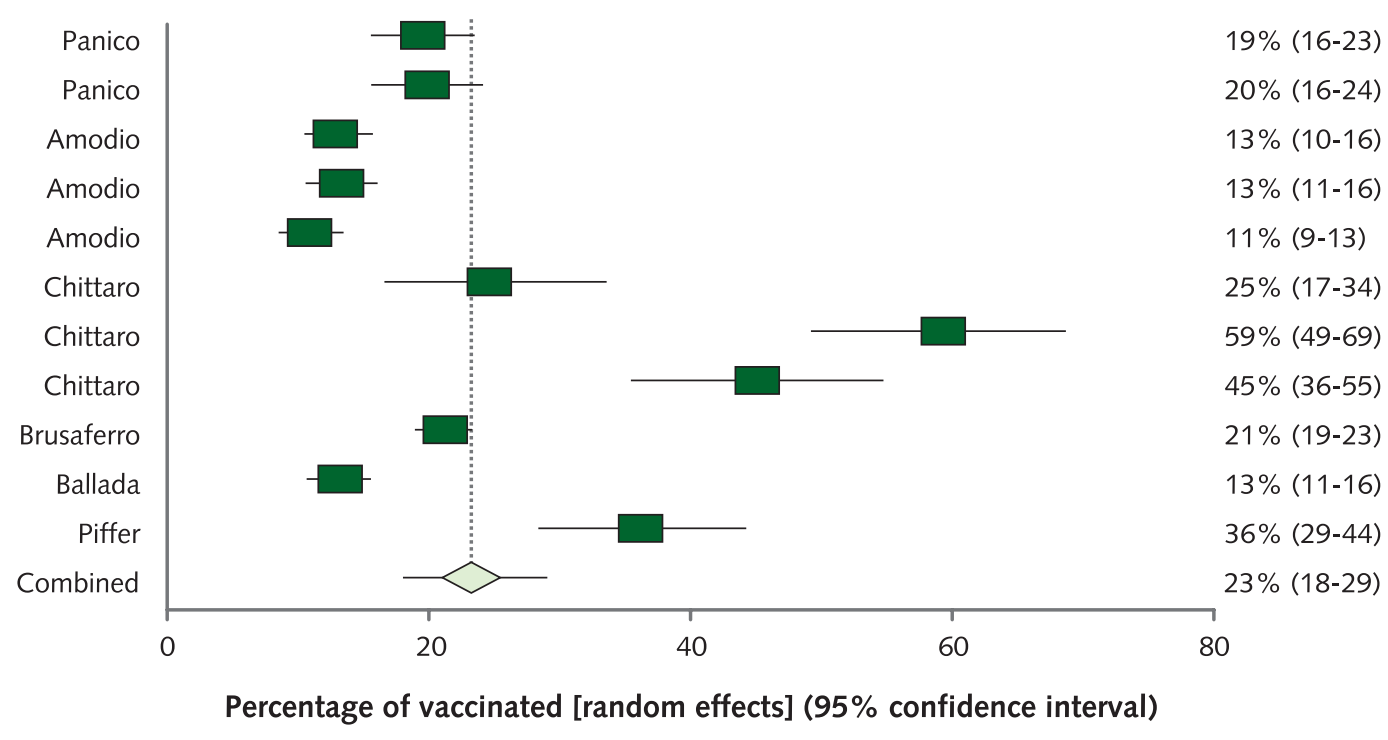

Figure 2. Forest plot of physicians for the prevalence of influenza vaccination among physicians

\section{Analysis of the reasons for and against vaccination}

Ideas encouraging and hampering vaccination are shown in Table III. Among these six papers, only one [5] presented physicians enhancing and preventing ideas about vaccination.

\section{Ideas encouraging vaccination}

Most physicians (91.2\%) know that the vaccine is protective, and self protection appears to be a good motivation (77.5\%), followed by patients' protection $(37.8 \%)$, family's protection $(34.4 \%)$ and protection of other people (33\%). It's important to notice that not all physicians think that vaccine is protective, and while many of them want to protect themselves, only few care about patients, family and other people, which is not exactly reassuring. Moreover, it is strange that physicians do not take into account that fragile and sensitive patients have a higher risk associated to influenza compared to ordinary

\begin{tabular}{|lc|}
\hline \multicolumn{1}{|l|}{ Ideas encouraging influenza vaccination } & $\%(\mathrm{~N})$ \\
\hline Vaccine is protective & $91.2(708)$ \\
\hline Self protection & $77.5(162)$ \\
Patients' protection & $37.8(79)$ \\
Family's protection & $34.4(72)$ \\
Protection of other people & $33(69)$ \\
$\quad$ Ideas hampering influenza vaccination & \\
Doesn't care about influenza & $56.2(300)$ \\
Doubts about vaccine efficacy & $8.9(44)$ \\
Fear of adverse effects & $7.5(40)$ \\
Vaccine isn't protective & $6.9(54)$ \\
\hline
\end{tabular}

Table III. Distribution of ideas about influenza vaccination, derived from Ballada [5] people.

\section{Ideas preventing vaccination}

Not caring about influenza (56.2\%) appears clearly to be the most frequent answer (as well as the main problem). It is worrying that such a great part of physicians simply doesn't care about this problem, despite recommendations from Ministry of Health and international organisations. Other less strong reasons examined are doubts about vaccine efficacy (8.9\%), fear of adverse effects (7.5\%), and the belief that vaccine is not protective $(6.9 \%)$. 


\section{Discussion}

Italy has a good overall influenza vaccination coverage, and national records for population aged over 65 years or with chronic illness are available [8]. Unfortunately, despite the ministerial recommendation, there isn't any national record regarding HCWs' or physicians' vaccination. In fact the results show a mean prevalence of vaccination that is low if compared to other European Countries (ranging from $15 \%$ to $29 \%$ in Countries such as UK, Germany, France, Spain), while it becomes high if we consider the population aged over 65 years and chronic illness.

The result of this analysis suggests that physicians' vaccination for seasonal influenza in Italy seems to be of little interest. The most recurring reason provided by physicians is simply "I do not care about influenza." These answers show dangerous disinformation and scarce knowledge of the problem and, coming from the people who have a main role in preventing this disease and in taking care of their patiens, protecting them as best as they can, is really worrying. Furthermore, when they get vaccinated it's more often because of self protection, rather than for their patients'.

Moreover, some physicians doubt about vaccine efficacy or have too much fear of adverse effects [5]. Adequate knowledge given by vaccination campaign can reduce this kind of problems. This idea is also confirmed observing higher vaccination rate among physicians [5,25] (who have a better knowledge of influenza and vaccination) rather than among nurses and ancillary workers.

Barriers such as "not caring about influenza," "fear of adverse effects" and "belief that vaccine isn't effective" appear strong but can be matched through well-done campaigns which can achieve good results. As an example, particularly encouraging results have been obtained through vaccination in the ward [27], which appears efficient in making physicians and other HCWs more aware of the importance of immunization, with a great increase of vaccination prevalence. Maybe this could be the direction in which vaccination campaigns should move.

Limitations of this study are that only one paper has examined the reasons behind vaccination, so that population is not as wide as the one studied for the prevalence among physicians. Another bias could be represented by the responders them-

Questions for further research

It could be interesting to investigate methods and tools to enhance HCW's knowledge about influenza vaccines, and to perform well-done sensitization campaign for its prevention among physicians selves, due to their characteristic of answering to a questionnaire: this can aimlessly select physicians who care more than the average about the others, granting results better than reality.

The strength of this study is the large size of the responders which can guarantee a reliable picture of the situation at the national level.

The review in brief

\begin{tabular}{|c|c|}
\hline Clinical question & Pooled prevalence of influenza vaccination among physicians in Italy \\
\hline Type of review & Systematic (meta-analysis) \\
\hline Search of the literature & Scopus, PubMed and Google Scholar \\
\hline Conclusions & $\begin{array}{l}\text { Prevalence of vaccinates among physicians }=23.18 \% ; 95 \% \mathrm{Cl}=17.85-28.98 \% \text {. Reasons } \\
\text { hampering vaccination show a lack of concern about the severity of the disease and the } \\
\text { importance of prevention. Influenza vaccination coverage among physicians should therefore } \\
\text { be improved }\end{array}$ \\
\hline Limitations & Small population sample in the investigation of the vaccination barriers among physicians \\
\hline
\end{tabular}




\section{References}

1. Grandi P, Franco G. Practising evidence-based occupational health in workers' groups: how to prevent sickness absence caused by influenza. Occup Med 2005; 55: 7-9

2. Jordan R, Wake B, Hawker J, Boxall E, Fry-Smith A, Chen Y, et al. Influenza vaccination of health care workers (HCW) to reduce influenza-related outcomes in high risk patients: a systematic review of clinical and cost-effectiveness. Department of public health and epidemiology 2004, report 48

3. Colombo GL, Ferro A, Vinci M, Zordan M, Serra G. Cost-benefit analysis of influenza vaccination in a public healthcare unit. Ther Clin Risk Manag 2006; 36: 219-26

4. Esposito S, Bosis S, Pelucchi C, Tremolati E, Sabatini C, Semino M, et al. Influenza vaccination among healthcare workers in a multidisciplinary University hospital in Italy. BMC Public Health 2008; 8: 422

5. Ballada D, Biasio LR, Cascio G, D'Alessandro D, Donatelli I, Fara GM, et al. Attitudes and behavior of health care personnel regarding influenza vaccination. Eur J Epidemiol 1994; 10: 63-8

6. Piffer S, Filippetti F, Del Dot D, Cristofolini A. La copertura e l'atteggiamento verso la vaccinazione antinfluenzale negli operatori sanitari. Aree per un'azione specifica di promozione dell'attività vaccinale in uno studio pilota [Coverage and behaviour towards vaccination in health care workers. Areas for the promotion of specific action in vaccination activity through a pilot study]. Ann Ig 2000; 12: 347-54

7. Panico MG, D’Anna A, Ronga C. Knowledge, attitudes and behaviour of healthcare workers regarding influenza and vaccination in Salerno, Italy. Ital J Public Health 2010; 3 [in press]

8. Blank PR, Schwenkglenks M, Szucs TD. Influenza vaccination coverage rates in five European countries during season 2006/07 and trends over six consecutive seasons. BMC Public Health 2008; 8: 272

9. Baron G, De Wals P, Milord F. Vaccination practices of Quebec family physicians. Influenza vaccination status and professional practices for influenza vaccination. Can Fam Physician 2001; 47: 2261-6

10. Ester RT, McGeer A, Tomlinson G, Detsky AS. Use of, effectiveness of, and attitudes regarding influenza vaccine among house staff. Infect Control Hosp Epidemiol 2003; 24: 839-44

11. Halliday L, Thomson JA, Roberts L, Bowen S, Mead C. Influenza vaccination of staff in aged care facilities in the ACT: how can we improve the uptake of influenza vaccine? Aust N Z J Public Health 2003; $27: 70-5$

12. La Torre G, Chiaradia G, Gianfagna F, De Laurentis A, Boccia S, Ricciardi W. Quality assessment in meta-analisys. Ital J Public Health 2006; 3: 44-50

13. Angelillo IF, Villari P. Residential exposure to electromagnetic fields and childhood leukaemia: a meta-analisys. Bull World Health Organ 1999; 77: 906-15

14. Stuart A, Ord JK. Kendall's advanced theory of statistics ( $6^{\text {th }}$ edition). London: Edward Arnold, 1994

15. DerSimonian R, Laird N. Meta-analysis in Clinical Trials. Control Clin Trials 1986; 7: 177-88

16. National Health and Medical Research Council. How to review the evidence: systematic identification and review of the scientific literature. Handbook series on preparing clinical practice guidelines. Camberra: Biotext, November 1999

17. Higgins JPT, Thompson SG. Quantifying heterogeneity in a meta-analysis. Stat Med 2002; 21: 1539-58

18. Higgins JPT, Thompson SG, Deeks JJ, Altman DG. Measuring inconsistency in meta-analyses. $\mathrm{Br}$ Med J 2003; 327: 557-60

19. Liberati A, Altman DG, Tetzlaff J, Murlow C, Gøtzsche PC, Ioannidis JPA, et al. The PRISMA statement for reporting systematic reviews and meta-analyses of studies that evaluate health care interventions: explanation and elaboration. Ital J Public Health 2009; 6: 354-91 
20. Jefferson T. Influenza vaccination: policy versus evidence. $B M J$ 2006; 333: 912-5

21. Brusaferro S, Chittaro M, De Carli G, Raffaele B, Puro V. Italian hospitals policies for the prevention of influenza in health care workers. J Prev Med Hyg 2004; 45: 9-11

22. Amodio E, Anastasi G, Di Pasquale M, Gelsomino V, Morici M, Romano N, et al. Influenza vaccination among healthcare workers and absenteeism from work due to influenza-like illness in a teaching hospital in Palermo. Ital J Public Health 2010; 3(in press)

23. Fanetti AC, Mascione R, Cecconi ER, Toia E, Tonelli F, Carrer P. Influenza vaccination in health care workers of a university hospital in Milan. G Ital Med Lav Ergon 2007; 29: 764-5

24. Calisto ML, Spataro P, Ventura Spagnolo E, Mattace Raso M, Cannavò G, Picerno I. Knowledge and practice of the influenza vaccination among healthcare workers in the hospital unit of Messina. $J$ Prev Med Hyg 2002; 43: 17-22

25. La Torre G, Di Thiene D, Cadeddu C, Ricciardi W, Boccia A. Behaviours regarding preventive measures against pandemic H1N1 influenza among Italian healthcare workers, October 2009. Euro Surveill 2009; 14(49): pii $=19432$

26. Chittaro M, Turello D, Calligaris L, Farneti F, Faruzzo A, Fiappo E, et al. Impact of vaccinating HCWs on the ward and possible influence of avian flu threat. Infection 2009; 37: 29-33

27. Nicholson KG, Snacken R, Palache MA. Influenza immunization policies in Europe and the United States. Vaccine 1995; 13: 365-9

28. Rizzuto E, Prete AM, Virtuani L, Pompa MG. Effectiveness of influenza vaccination: A survey within the Italian Ministry of Health personnel. Vaccine 2006; 24: 6612-4

29. Di Giuseppe G, Nobile CGA, Marinelli P, Angelillo IF. A survey of knowledge, attitudes, and behavior of Italian dentists toward immunization. Vaccine 2007; 25: 1669-75 